\title{
Density Functional Theory (B3LYP/6-311+G(d, p)) Study of Stability, Tautomerism and Acidity of 2-Thioxanthine in Gas and Aqueous Phases
}

\author{
Assoma Amon Benjamine*, Koné Mawa, Alao Latifatou Laye, Bede Affoué Lucie, Koné Soleymane, \\ N'Guessan Boka Robert, Bamba El Hadji Sawaliho, N'guessan Yao Thomas
}

Training and Research Unit of Sciences of Structures of Matter and Technology (UFR SSMT), Félix Houphouët-Boigny University, Abidjan, Côte-d'Ivoire

\author{
Email address: \\ benassoma@yahoo.fr (A. A. Benjamine) \\ ${ }^{*}$ Corresponding author
}

\section{To cite this article:}

Assoma Amon Benjamine, Koné Mawa, Alao Latifatou Laye, Bede Affoué Lucie, Koné Soleymane, N'Guessan Boka Robert, Bamba El Hadji Sawaliho, N'guessan Yao Thomas. Density Functional Theory (B3LYP/6-311+G(d, p)) Study of Stability, Tautomerism and Acidity of 2-Thioxanthine in Gas and Aqueous Phases. International Journal of Computational and Theoretical Chemistry.

Vol. 7, No. 1, 2019, pp. 49-55. doi: 10.11648/j.ijctc.20190701.17

Received: January 31, 2019; Accepted: March 15, 2019; Published: April 3, 2019

\begin{abstract}
This work is a contribution of theoretical chemistry to the knowledge of 2-thioxanthine's properties. Its aim first consists in checking the chemistry's results related to the exploitation of semi-empirical methods; it provides theoretical data on the acidity of 2-thioxanthine tautomers. To do this, the DFT method with the B3LYP functional, associated with the $6-311+\mathrm{G}(\mathrm{d}, \mathrm{p})$ basis set was used. The aqueous phase was modelled with the Polarizable Continuum Model (PCM). The results show that in gas and aqueous phases 2-thioxanthine can exist as a mixture of four tautomers $2 \mathrm{TX}(1,3,7), 2 \mathrm{TXX}(1,3,9)$, $2 \mathrm{TX}(1,7,10)$ and $2 \mathrm{TX}(1,9,10)$. The relative stability decreases in the order $2 \mathrm{TX}(1,3,7)>2 \mathrm{TX}(1,3,9)>2 \mathrm{TX}(1,9,10)>$ $2 \mathrm{TX}(1,7,10)$. This work establishes that the tautomer $2 \mathrm{TX}(1,9,10)$ comes from the $2 \mathrm{TX}(1,3,7)$ via the $2 \mathrm{TX}(1,3,9)$ one. It demonstrates that the acidity of the most stable tautomer's nitrogen $2 \mathrm{TX}(1,3,7)$, decreases in the order $7>3>1$ in gas phase and in the order $3>7>1$ in aqueous phase. It provides data to elucidate the mechanisms to understand biological activities of 2-thioxanthine.
\end{abstract}

Keywords: 2-Thioxanthine, Stability, Tautomerism, Acidity, B3LYP

\section{Introduction}

2-Thioxanthine is a derivative of xanthine in which the oxygen atom in the 2-position is replaced by a sulfur atom. It is based on thiopurines, which are rare components of t-RNA. Some of them possess important biological and pharmacological properties [1-10]. The similarity of their structures to those of oxopurines permits their recognition by proteins and their incorporation in nucleic acids [1-3]. Sulfur-substitued nucleic acid bases have been developed as clinical drugs [11-15], where 2-thioxanthine evoles intensives intrests. Recently, 2-thioxanthine was the subject of an experimental study that allowed its determination from electrochemical sensor modified using poly-melamine and polyglutamic [16].

Most of the activities of thiopurines is expected to depend on the tautomeric équilibrium of the molécule $[17,18]$. Several experimental studies are reported on the tautomerism of 2-thioxanthine in literature. Indeed 2-thioxanthine has 14 shapes and three types of equilibria can be observed: keto $\rightleftarrows$ enol, thione $\rightleftarrows$ thiol and N7(H) $\rightleftarrows \mathrm{N} 9(\mathrm{H})$. The UV spectra of 2-thioxanthine shows that the predominant tautomer exists in an oxothione form with the imidazole proton on N9-H [19]. Additionaly, ${ }^{1} \mathrm{HNMR}$ measurements establish that the predominant tautomer exists in an oxothione form with the imidazole proton on $\mathrm{N}(7)$ [20]. Although this molecule has been the subject of several researches, the theoretical ones of Pervin Unal Civcir have given a renewed interest. It has been studied by the semiempirical calculation methods AM1 and PM3, 2-thioxanthine [21], 6-thioxanthine [22], 2,6-dithioxanthine [23] and other 
molecules [24,25]. The research establishes that for 2-thioxanthine, the oxothione $\mathrm{N} 7(\mathrm{H})$ form is more stable than the oxothione $\mathrm{N} 9(\mathrm{H})$ form in the gas phase while the oxothione $\mathrm{N} 9(\mathrm{H})$ form is predominant in aqueous phase [21]. $\mathrm{Li}$ [26] did the same investigations with B3LYP/6-311G(d,p) method, he also show that oxothione $\mathrm{N} 7(\mathrm{H})$ form is the most stable tautomer while $\mathrm{N} 9(\mathrm{H})$ form is the next.

The verification of semi-empirical methods' chemistry results remains at the centre of our team's concern. Furthermore, to our knowledge, there are no theoretical data on the acidity of 2-thioxanthine. To do this, we use DFT method with the B3LYP functional. This process yields convincing results for 6-thioxanthine, dithioxanthine and xanthine [27-29]. In this impetus, the present research aims to question those deducted from semi-empirical methods relating to 2-thioxanthine. Specifically, it focused on the stability, tautomerism and acidity of its tautomers.

\section{Methods of Calculation}

All calculations were carried out with DFT (B3LYP functional) using $6-311+\mathrm{G}(\mathrm{d}, \mathrm{p})$ basis set [30], as incorporated in the GAUSSIAN-03 program [31]. In aqueous phase, the solvation model Polarizable Continuum Model (PCM) was used [32, 33]. The geometries of tautomers, transition states and intermediates have been fully optimized. The Gibbs free energies are obtained from the calculation of the frequencies. Frequency analyses were proceeded to confirm the structure being a minimum or a transition state (i.e without or with solely an imaginary frequency). To name the 14 tautomeric forms we have used the following notations: $2 \mathrm{TX}(\mathrm{i}, \mathrm{j}, \mathrm{k})$ where $\mathrm{i}, \mathrm{j}$, and $\mathrm{k}$ stand for the amount of the nitrogen, oxygen or sulfur atoms to which the hydrogen is attached (Figure 1).

Moreover, to establish the presence of a tautomerism, this work determines, first of all, the possible equilibriums. Then, it highlights those that are likely to exist. It calculates their constants and their activation energies. The following section presents the results obtained.

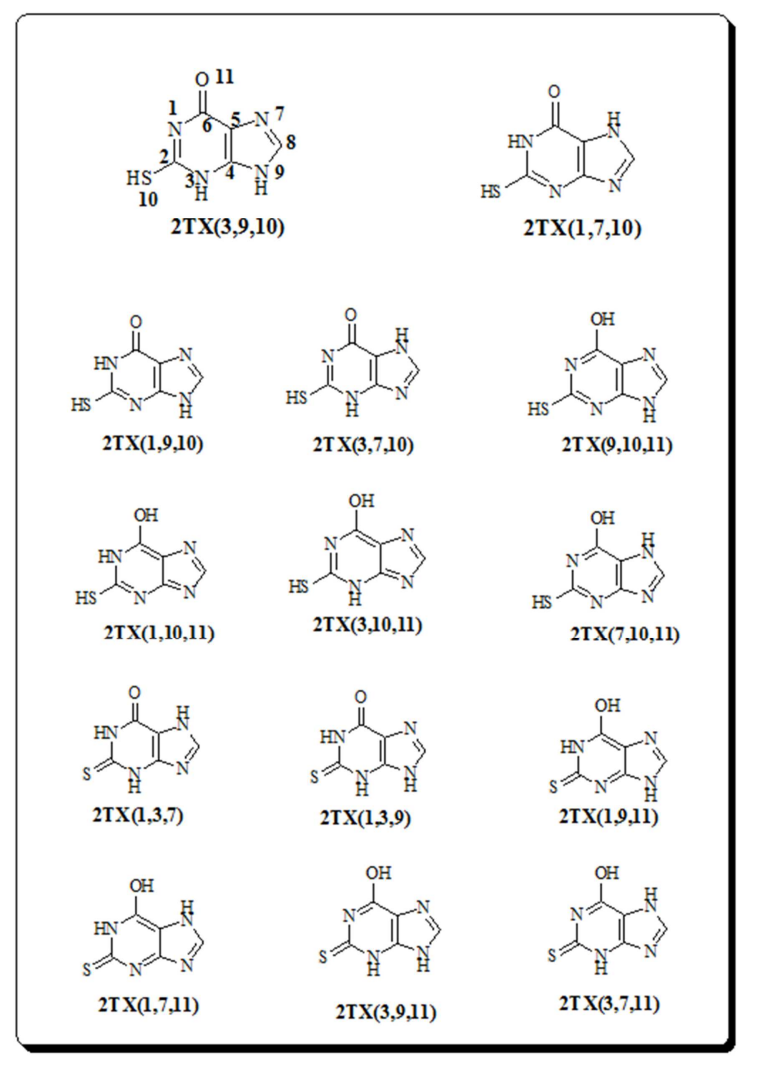

Figure 1. Tautomers of 2-Thioxanthine.

\section{Results and Discussions}

The results concern the stability, the tautomerism of 2-thioxanthine and the acidity of its heteroatoms.

\subsection{Stability of 2-Thioxanthine's Tautomers}

The Gibbs free energy, at computational level B3LYP/6-311+G(d, p), helps to discuss the relative stability of the 14 tautomers shown in Figure 1. Table 1 summarizes its values; $\Delta \mathrm{G}$ is the difference between the Gibbs free energy of the most stable tautomer $2 \operatorname{TX}(1,3,7)$ and those of the others $[34,35]$.

Table 1. Gibbs Free Energy $G($ a. u) and $\Delta G(\mathrm{kcal} / \mathrm{mol})$ at $T=298,15 \mathrm{~K}$.

\begin{tabular}{|c|c|c|c|c|}
\hline \multirow{2}{*}{ Tautomères } & \multicolumn{2}{|l|}{ Gas phase } & \multicolumn{2}{|c|}{ Aqueous phase } \\
\hline & Gg (au) & $\Delta \mathrm{Gg}(\mathrm{Kcal} / \mathrm{mol})$ & Gaq (au) & $\Delta \mathrm{Gaq}(\mathrm{Kcal} / \mathrm{mol})$ \\
\hline $2 \mathrm{TX}(3,9,10)$ & -885.450279 & 26.39 & -885.508951 & 16.76 \\
\hline $2 \mathrm{TX}(1,7,10)$ & -885.475589 & 10.51 & -885.520461 & 9.54 \\
\hline $2 \mathrm{TX}(1,9,10)$ & -885.477139 & 9.54 & -885.520865 & 9.28 \\
\hline $2 \mathrm{TX}(3,7,10)$ & -885.468658 & 14.86 & -885.514217 & 13.46 \\
\hline $2 \mathrm{TX}(9,10,11)$ & -885.472897 & 12.20 & -885.511687 & 15.04 \\
\hline $2 \mathrm{TX}(1,10,11)$ & -885.430981 & 38.50 & -885.492285 & 27.22 \\
\hline $2 \mathrm{TX}(7,10,11)$ & -885.468590 & 14.90 & -885.510371 & 15.87 \\
\hline $2 \mathrm{TX}(1,3,7)$ & -885.492344 & 0.00 & -885.535661 & 0.00 \\
\hline $2 \mathrm{TX}(1,3,9)$ & -885.479001 & 8.37 & -885.53203 & 2.28 \\
\hline $2 \operatorname{TX}(1,9,11)$ & -885.451139 & 25.86 & -885.513096 & 14.16 \\
\hline $2 \mathrm{TX}(1,7,11)$ & -885.440027 & 32.83 & -885.508762 & 16.88 \\
\hline $2 \mathrm{TX}(3,9,11)$ & -885.458153 & 21.45 & -885.514865 & 13.05 \\
\hline $2 \mathrm{TX}(3,7,11)$ & -885.468658 & 14.86 & -885.517589 & 11.34 \\
\hline
\end{tabular}

$\Delta \mathrm{Gg}: \Delta \mathrm{G}$ in the gas phase, $\Delta \mathrm{Gaq}: \Delta \mathrm{G}$ in the aqueous phase 
The discussion focuses on the gas phase at first. The results in Table 1 show that the oxothione tautomer $2 \mathrm{TX}(1,3,7)$ is the most stable of the 14 tautomers. The oxothione $2 \mathrm{TX}(1,3,9)$ follows it. Their energy differs from $8.37 \mathrm{kcal} / \mathrm{mol}$. The third most stable tautomer corresponds to the oxothiol $2 \mathrm{TX}(1,9,10)$. Its relative energy is $9.54 \mathrm{kcal} / \mathrm{mol}$. The fourth more stable tautomer is the oxothiol tautomer $2 \mathrm{TX}(1,7,10)$, which is $10.51 \mathrm{kcal} / \mathrm{mol}$ above the $2 \mathrm{TX}(1,3,7)$. According to Mesey and al [34,35], $10 \mathrm{kcal} / \mathrm{mol}$ is a reasonable limit for predicting the presence of stable species. This work suggests that 2-thioxanthine can exist in the gas phase under a mixture of four tautomers that are $2 \mathrm{TX}(1,3,7)$, $2 \mathrm{TX}(1,3,9), 2 \mathrm{TX}(1,9,10)$ and $2 \mathrm{TX}(1,7,10)$; but the tautomer $2 \mathrm{TX}(1,7,10)$ can exist in small amount at room temperature. The relative stability decreases in the order $2 \mathrm{TX}(1,3,7)>$ $2 \operatorname{TX}(1,3,9)>2 \operatorname{TX}(1,9,10)>2 \operatorname{TX}(1,7,10)$. Thus the most stables tautomers are oxothione forms.

Comparing the previous finding with those of the aqueous phase, it is observed that the Gibbs free energy difference is positive for all the tautomers except for two tautomers that are enolthiol $2 \mathrm{TX}(9,10,11)$ and $2 \mathrm{TX}(7,10,11)$. This result suggests that the presence of water helps to stabilize them with a clear stabilization of tautomers $2 \mathrm{TX}(1,3,9)$ and $2 \mathrm{TX}(1,7,10)$. The Gibbs free energy difference of tautomers $2 \mathrm{TX}(1,3,9), 2 \mathrm{TX}(1,7,10)$ and $2 \mathrm{TX}(1,9,10)$ with the most stable tautomer $2 \mathrm{TX}(1,3,7)$ is $2.28 ; 9.54$ and $9.28 \mathrm{kcal} / \mathrm{mol}$ respectively. In this state, according to Mezey et al $[34,35]$, four tautomers can exist in order of decreasing stability following $2 \mathrm{TX}(1,3,7)>2 \mathrm{TX}(1,3,9)>2 \mathrm{TX}(1,9,10)>$ $2 \mathrm{TX}(1,7,10)$. The existence of these tautomers had already been predicted by Civcir [21] but with a different order of stability: $2 \operatorname{TX}(1,3,7)>2 \operatorname{TX}(1,9,10)>2 \mathrm{TX}(1,7,10)$. > $2 \mathrm{TX}(1,3,9)$, in the gas phase and $2 \mathrm{TX}(1,3,9)>2 \mathrm{TX}(1,3,7)>$ $2 \mathrm{TX}(1,9,10)>2 \mathrm{TX}(1,7,10)$, in aqueous phase. The DFT/B3LYP/6-311+G(d, p) method we used is more elaborate, so the resulting orders of stability are the most likely.

\subsection{Tautomerism of 2-Thioxanthine}

To evaluate the tautomerism of 2-thioxanthine, we first consider the possible equilibriums between the potential tautomers and then we calculate the equilibrium constants and activation energies.

\subsubsection{Probable Tautomeric Equilibriums in 2-Thioxanthine}

Most therapeutic activities of thiopurines depend on potential equilibriums between their tautomeric forms [17, 18]. Here, it is accepted that the exchange of hydrogen atoms remains possible only between neighbouring heteroatoms or separated by at most two atoms. Moreover, this research prohibits simultaneous transfers of more than two hydrogen atoms. Under these conditions, there are four potential equilibriums between the most stable tautomers of 2-thioxanthine. The Figure 2 shows that the most stable tautomer $2 \mathrm{TX}(1,3,7)$ can be in equilibrium with $2 \mathrm{TX}(1,7,10)$ or $2 \mathrm{TX}(1,3,9)$. The tautomer $2 \mathrm{TX}(1,7,10)$ can also be in equilibrium with $2 \mathrm{TX}(1,9,10)$, which is itself with 2TX $(1,3,9)$. Their actual existence suggests calculating their constants and activation energies.

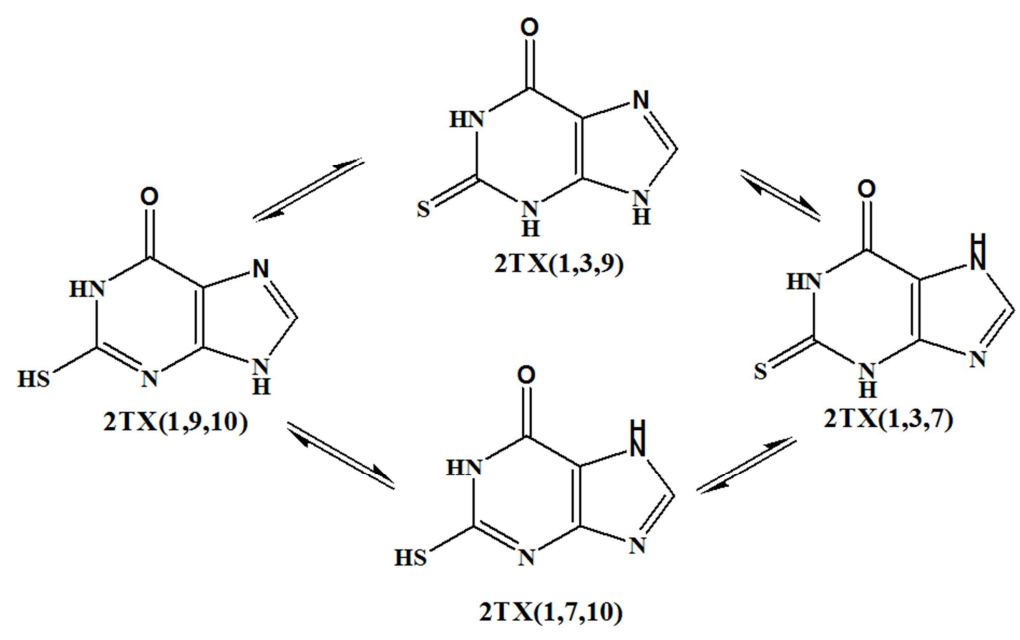

Figure 2. Possible equilibriums between the most stable tautomers of 2-Thioxanthine.

\subsubsection{Tautomeric Equilibrium Constants}

A chemical equilibrium between two tautomers A and B $(\mathrm{A} \rightleftarrows \mathrm{B})$ is characterized by its constant $\mathrm{K}_{\mathrm{T}}$. The calculation of $\mathrm{K}_{\mathrm{T}}$ makes it possible to highlight the real 2-thioxanthine's tautomeric equilibrium. $\mathrm{K}_{\mathrm{T}}$ 's values are obtained with the relation:

$$
\mathrm{K}_{\mathrm{T}}=\exp \left(-\frac{\Delta \mathrm{G}}{\mathrm{RT}}\right)
$$

The Table 2 collects the $\mathrm{K}_{\mathrm{T}}$ values in gas or aqueous phase at B3LYP/6-311+G(d, p).

Table 2. Equilibrium Constants $K_{T}$ at $T=298,15 \mathrm{~K}$.

\begin{tabular}{lll}
\hline Equilibrium & $\mathbf{K}_{\mathrm{Tg}}$ & $\mathbf{K}_{\mathrm{Taq}}$ \\
\hline $2 \operatorname{TX}(1,9,10) \rightleftarrows 2 \mathrm{TX}(1,3,9)$ & 7.19 & $1.37 \cdot 10^{5}$ \\
$2 \operatorname{TX}(1,3,9) \rightleftarrows 2 \mathrm{TX}(1,3,7)$ & $1.37 \cdot 10^{6}$ & $4.68 \cdot 10^{1}$ \\
$2 \operatorname{TX}(1,9,10) \rightleftarrows 2 \operatorname{TX}(1,7,10)$ & $1.94 \cdot 10^{-1}$ & $6.52 \cdot 10^{-1}$ \\
$2 \operatorname{TX}(1,7,10) \rightleftarrows 2 \operatorname{TX}(1,3,7)$ & $5.10 \cdot 10^{7}$ & $9.82 \cdot 10^{6}$ \\
\hline
\end{tabular}


When $\mathrm{K}_{\mathrm{T}}<10^{-4}$, the form $\mathrm{A}$ exists alone. If $\mathrm{K}_{\mathrm{T}}>10^{4}$, compound $\mathrm{B}$ predominates. The equilibrium becomes effective if $\mathrm{K}_{\mathrm{T}}$ ranging from $10^{-4}$ to $10^{4}$.

The $\mathrm{K}_{\mathrm{T}}$ value of the $2 \mathrm{TX}(1,3,9) \rightleftarrows 2 \mathrm{TX}(1,3,7)$ and $2 \mathrm{TX}(1,7,10) \rightleftarrows 2 \mathrm{TX}(1,3,7)$ processes are respectively 1.37 $10^{6}$ and $5.1010^{7}$ in the gas phase; they suggest a clear stability of $2 \mathrm{TX}(1,3,7)$ in equilibrium; it can't be transformed into the forms $2 \mathrm{TX}(1,3,9)$ and $2 \mathrm{TX}(1,7,10)$. The $2 \mathrm{TX}(1,9,10)$ $\rightleftarrows 2 \mathrm{TX}(1,3,9)$ and $2 \mathrm{TX}(1,9,10) \rightleftharpoons 2 \mathrm{TX}(1,7,10)$ processes have respective $\mathrm{K}_{\mathrm{T}}$ values of 7.19 and $1.94 \cdot 10^{-1}$. These values indicate that the tautomers are present in comparable quantities. the $\mathrm{K}_{\mathrm{T}}$ value of transformations $2 \mathrm{TX}(1,9,10) \rightleftharpoons$ $2 \mathrm{TX}(1,3,9)$ and $2 \mathrm{TX}(1,3,9) \rightleftarrows 2 \mathrm{TX}(1,3,7)$ passes respectively 7.19 and $1.3710^{6}$ in the gas phase at $1.3710^{5}$ and $4.6810^{1}$ in the aqueous one. This is due to the clear stabilization of tautomer $2 \mathrm{TX}(1,3,9)$ in this latter one. Nevertheless 2TX $(1,3,7)$ remains the most stable.

\subsubsection{Activation Energies of Possible Tautomeric Equilibriums}

The Figure 3 illustrates two access pathway to the most stable tautomer $2 \mathrm{TX}(1,3,7)$ starting from $2 \mathrm{TX}(1,9,10)$. The table 3 show the Gibbs free energies of all the species involved in tautomerism as well as the imaginary frequencies of the different transition states; these last quantities characterize them. The table 4 contains activation energies. This article also explains the energy profile of 2-thioxanthine's tautomerism (Figure 4)

In the first pathway (Figure 4), The hydrogen atom bonded to the sulfur atom S10 of the tautomer $2 \mathrm{TX}(1,9,10)$ transfers onto the nitrogen atom N3. This result carried out through the transition state TS1 with an energy barrier of $27.44 \mathrm{Kcal} / \mathrm{mol}$ to give $2 \mathrm{TX}(1,3,9)$. Then, in $2 \mathrm{TX}(1,3,9)$, the hydrogen atom bonded to the nitrogen atom N9 firstly transfers onto the carbon atom $\mathrm{C} 8$ via the transition state $\mathrm{TS} 2$, with an energy barrier of $47.63 \mathrm{Kcal} / \mathrm{mol}$ to give intermediate IM1. In the second step, the same hydrogen atom passes from this latter one onto tautomer $2 \mathrm{TX}(1,3,7)$ via the transition state TS3; this process corresponds an energy barrier of $28.43 \mathrm{Kcal} / \mathrm{mol}$.

In the other pathway, in $2 \mathrm{TX}(1,9,10)$, the hydrogen atom bonded to the nitrogen atom N9 firstly transfers onto the carbon atom $\mathrm{C} 8$. This displacement is realized through the transition state TS4, with an energy barrier of $54.17 \mathrm{Kcal} / \mathrm{mol}$ to give intermediate IM2, then it passes from IM2 onto tautomer $2 \mathrm{TX}(1,7,10)$ via the transition state TS5, with a barrier energy of $25.75 \mathrm{Kcal} / \mathrm{mol}$. Finally, the hydrogen atom bonded to the sulfur atom S10 in $2 \mathrm{TX}(1,7,10)$ transfers onto the nitrogen atom $\mathrm{N} 3$ via the transition state TS6, with an energy barrier of $23.15 \mathrm{Kcal} / \mathrm{mol}$ to give $2 \mathrm{TX}(1,3,7)$.

The highest activation energy in both pathways is obtained at the breaking of the bond $\mathrm{N} 9-\mathrm{H}(47.63$ and $54.17 \mathrm{Kcal} / \mathrm{mol}$ respectively). That of the second is $6.54 \mathrm{Kcal} / \mathrm{mol}$ higher than that of the first. This latter remains thus the most favourable for the reaction between 2-Thioxanthine's tautomers which may exist. In other words, the tautomerism is preferentially realized by the first pathway.

The preceding results make it possible to discuss the 2-thioxanthine's heteroatom acidity.

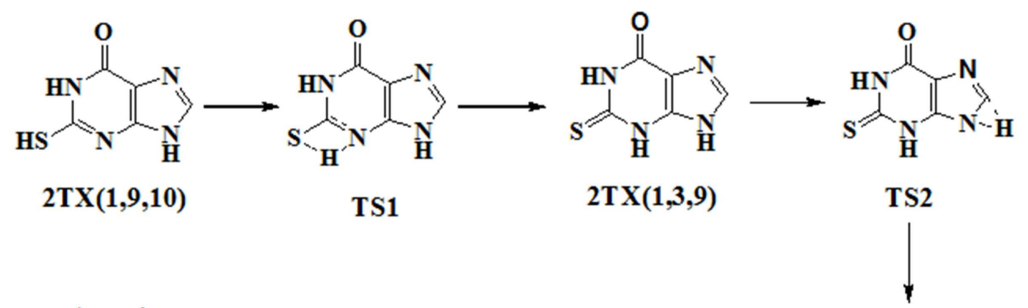

pathway 1

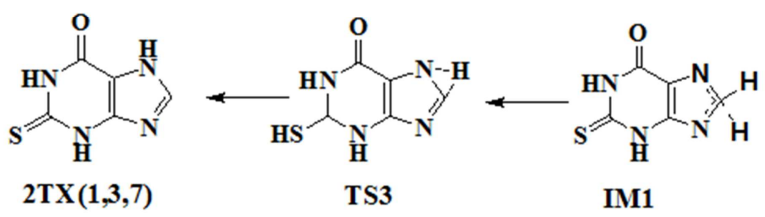

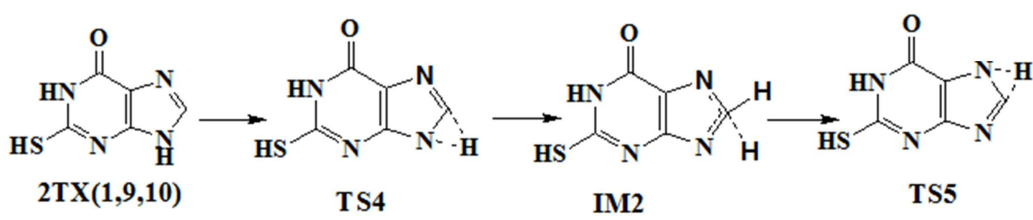

pathway 2

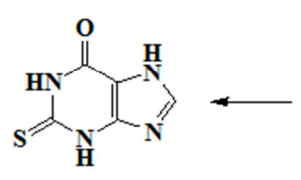

$2 \operatorname{TX}(1,3,7)$<smiles></smiles>

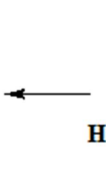

Figure 3. Potential Tautomerism of 2-Thioxanthine. 
This article also explains the energy profile of 2-Thioxanthine's tautomerism (Figure 4).

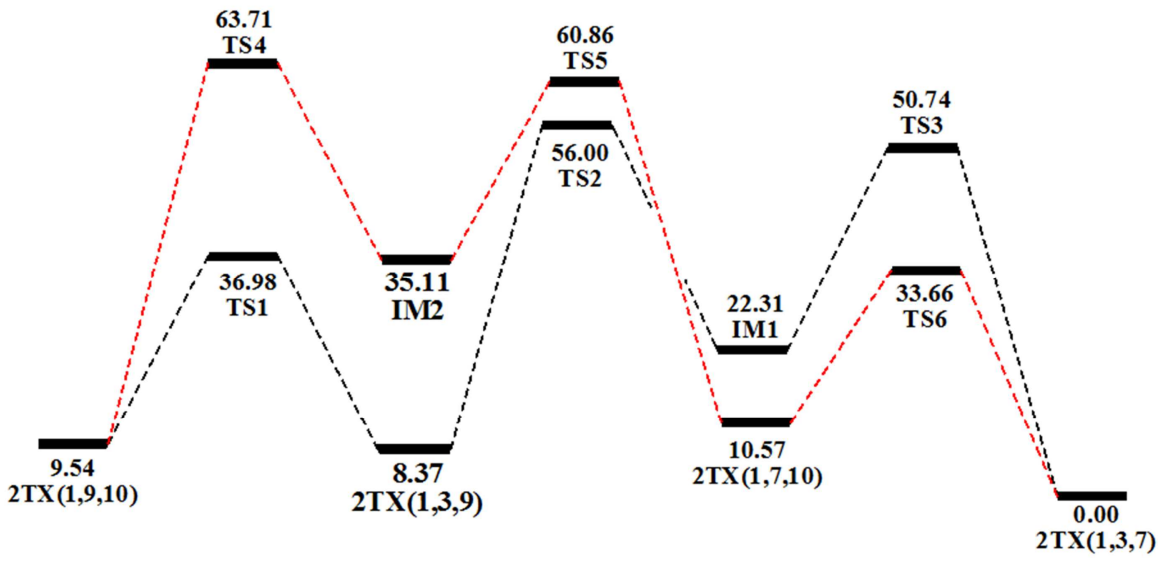

Figure 4. The relative Energy Profiles of the two pathways tautomerization of 2-thioxanthine.

Table 3. Gibbs Free Energies and Imaginary Frequencies in gas phase.

\begin{tabular}{llll}
\hline Espèces & $\mathbf{G}(\mathbf{a u})$ & $\begin{array}{l}\boldsymbol{\Delta G} \\
(\mathbf{k c a l} / \mathbf{m o l})\end{array}$ & $\begin{array}{l}\text { Imaginary } \\
\text { Frequencies }\end{array}$ \\
\hline 2TX(1,3,7) & -885.492344 & 0.00 & \\
2TX $(1,3,9)$ & -885.479001 & 8.37 & \\
2TX(1,7,10) & -885.475589 & 10.51 & \\
2TX(1,9,10) & -885.477139 & 9.54 & \\
IM1 & -885.456783 & 22.31 & \\
IM2 & -885.436393 & 35.11 & \\
TS1 & -885.433405 & 36.98 & -1654.94 \\
TS2 & -885.403097 & 56.00 & -1569.27 \\
TS3 & -885.411476 & 50.74 & -1498.04 \\
TS4 & -885.390822 & 63.71 & -1517.03 \\
TS5 & -885.395353 & 60.86 & -1474.53 \\
TS6 & -885.438701 & 33.66 & -1651.11 \\
\hline
\end{tabular}

Table 4. Activation Energies Ea (kcal/mol) in gas phase at $T=298,15 \mathrm{~K}$.

\begin{tabular}{lll}
\hline TS & Reactions & Ea $(\mathbf{k c a l} / \mathbf{m o l})$ \\
\hline TS1 & $2 \mathrm{TX}(1,9,10) \rightarrow 2 \mathrm{TX}(1,3,9)$ & 27.44 \\
TS2 & $2 \mathrm{TX}(1,3,9) \rightarrow \mathrm{IM} 1$ & 47.63 \\
TS3 & $\mathrm{IM} 1 \rightarrow 2 \mathrm{TX}(1,3,7)$ & 28.43 \\
TS4 & $2 \mathrm{TX}(1,9,10) \rightarrow \mathrm{IM} 2$ & 54.17 \\
TS5 & $\mathrm{IM} 2 \rightarrow 2 \mathrm{TX}(1,7,10)$ & 25.75 \\
TS6 & $2 \mathrm{TX}(1,7,10) \rightarrow 2 \mathrm{TX}(1,3,7)$ & 23.15 \\
\hline
\end{tabular}

\subsection{Acidity of the Potential Tautomers}

The tautomers of 2-thioxanthine have hydrogenated sites that may be deprotonated. The choice of these depends on the acid's strength [36]. The relative Gibbs free energy $(\Delta \mathrm{G})$ of the associated general reaction $\left(\mathrm{AH} \rightarrow \mathrm{A}^{-}+\mathrm{H}^{+}\right)$helps evaluate the 2-thioxanthine's heteroatom acidity.

$$
\begin{gathered}
\mathrm{AH} \rightarrow \mathrm{A}^{-}+\mathrm{H}^{+} \\
\Delta \mathrm{G}=\mathrm{G}\left(\mathrm{A}^{-}\right)+\mathrm{G}\left(\mathrm{H}^{+}\right)-\mathrm{G}(\mathrm{AH})
\end{gathered}
$$

In gas phase, $\mathrm{G}_{\mathrm{g}}\left(\mathrm{H}^{+}\right)=2.5$ RT- $\mathrm{T} \Delta \mathrm{S}=1.48-7.76 \mathrm{G}_{\mathrm{g}}\left(\mathrm{H}^{+}\right)=-$ $6,28 \mathrm{kcal} / \mathrm{mol}$ [37]

In aqueous phase, $\mathrm{G}_{\mathrm{aq}}\left(\mathrm{H}^{+}\right)$is calculated from the relation:

$$
\mathrm{G}_{\mathrm{aq}}\left(\mathrm{H}^{+}\right)=\mathrm{G}_{\mathrm{g}}\left(\mathrm{H}^{+}\right)+\mathrm{G}_{\mathrm{solv}}\left(\mathrm{H}^{+}\right)
$$

$\mathrm{G}_{\text {solv }}$ is the Gibbs free energy of solvation, $\mathrm{G}_{\text {solv }}\left(\mathrm{H}^{+}\right)=-$ $263.47 \mathrm{kcal} / \mathrm{mol}[38]$.
Table 5 presents the results of the calculations.

The acidity of tautomeric sites is related to the value of $\Delta \mathrm{G}$ [36]. The weaker this is, the more the heteroatom of the position concerned is acidic. Under these conditions, in the gas phase, the nitrogen $\mathrm{N} 7$ of the imidazole ring is the most acid site of the tautomer $2 \mathrm{TX}(1,3,7)$. The nitrogen N9 is the most acid one of $2 \mathrm{TX}(1,3,9)$ and sulfur $\mathrm{S} 10$ that of $2 \mathrm{TX}(1,7,10)$ and $2 \mathrm{TX}(1,9,10)$. In the aqueous one the nitrogen $\mathrm{N} 3$ of the pyrimidine ring becomes the most acid site of $2 \mathrm{TX}(1,3,7)$ and $2 \mathrm{TX}(1,3,9)$. At the same time, sulfur S10 remains the most acid site of $2 \mathrm{TX}(1,7,10)$ and $2 \mathrm{TX}(1,9,10)$

In the end, the acidity of the most stable tautomer $2 \mathrm{TX}(1,3,7)$ decreases in the order $7>3>1>8$, in gas phase and in the order $3>7>1>8$ in aqueous phase.

Table 5. $\Delta G(\mathrm{Kj} / \mathrm{mol})$ of Potential Tautomers.

\begin{tabular}{lll}
\hline Tautomers & $\boldsymbol{\Delta G}$ & $\boldsymbol{\Delta G a q}$ \\
\hline $2 \mathrm{TX}(1,3,7)$ & 329.01 & \\
$\mathrm{~N}_{1}$ & 322.09 & 19.43 \\
$\mathrm{~N}_{3}$ & 314.15 & 15.47 \\
$\mathrm{~N}_{7}$ & 350.56 & 16.92 \\
$\mathrm{C}_{8}$ & & 47.85 \\
$2 \mathrm{TX}(1,3,9)$ & 330.08 & \\
$\mathrm{~N}_{1}$ & 310.78 & 20.04 \\
$\mathrm{~N}_{3}$ & 305.75 & 12.17 \\
$\mathrm{~N}_{9}$ & 354.65 & 14.66 \\
$\mathrm{C}_{8}$ & & 49.74 \\
$2 \mathrm{TX}(1,7,10)$ & 321.76 & \\
$\mathrm{~N}_{1}$ & 323.53 & 18.22 \\
$\mathrm{~N}_{7}$ & 311.59 & 19.77 \\
$\mathrm{~S}_{10}$ & 361.47 & 5.96 \\
$\mathrm{C}_{8}$ & & 50.70 \\
$2 \mathrm{TX}(1,9,10)$ & 325.68 & \\
$\mathrm{~N}_{1}$ & 323.02 & 18.87 \\
$\mathrm{~N}_{9}$ & 309.60 & 20.03 \\
$\mathrm{~S}_{10}$ & 364.87 & 5.15 \\
$\mathrm{C}_{8}$ & & 52.32 \\
\hline
\end{tabular}

\section{Conclusion}

The study concerns the stability, tautomerism and acidity of 2-thioxanthine from literature results. In particular, it relies 
on elaborate methods of theoretical chemistry to take stock of its tautomeric forms and the acidity of its heteroatoms.

Its results establish that 2-thioxanthine can exist in gas and aqueous phases as a mixture of four tautomers $2 \mathrm{TX}(1,3,7)$, $2 \operatorname{TXX}(1,3,9), 2 \operatorname{TX}(1,7,10)$ and $2 \operatorname{TXX}(1,9,10)$. In the gas phase the tautomer $2 \mathrm{TX}(1,7,10)$ can exist in small amount at room temperature. The tautomer $2 \mathrm{TX}(1,3,7)$, is the most stable in both phases.

The equilibrium constant reveals that in the gas phase, only the tautomeric equilibrium $2 \mathrm{TX}(1,9,10) \rightleftarrows 2 \mathrm{TX}(1,3,9)$ and $2 \mathrm{TX}(1,9,10) \rightleftarrows 2 \mathrm{TX}(1,7,10)$ are possible. In the presence of water, the equilibrium $2 \mathrm{TX}(1,3,9) \rightleftarrows$ $2 \operatorname{TX}(1,3,7)$ is superimposed on that of $2 \mathrm{TX}(1,9,10) \rightleftarrows$ $2 \mathrm{TX}(1,7,10)$. This work suggests that the biological activity of 2-thioxanthine relies on these two mainly tautomeric equilibrium.

Activation energies in the gas phase show that the 2-thioxanthine's tautomerization is realized by the transformation of tautomer $2 \mathrm{TX}(1,9,10)$ to $2 \mathrm{TX}(1,3,7)$ through $2 \mathrm{TX}(1,3,9)$.

In terms of acidity, research establishes that in the gas phase, N7 represents the most acidic atom of tautomer $2 \mathrm{TX}(1,3,7)$. The nitrogen N9 corresponds to that of $2 \operatorname{TX}(1,3,9)$ whereas the sulfur S10 that of $2 \operatorname{TX}(1,7,10)$ and $2 \mathrm{TX}(1,9,10)$. In aqueous phase, this work shows that the results are preserved except those of $2 \mathrm{TX}(1,3,7)$ and $2 \mathrm{TX}(1,3,9)$; for these tautomers, N3 becomes the most acidic. In addition, this study indicates that the acidity of the most stable tautomer $2 \mathrm{TX}(1,3,7)$ decreases in the order $7>3>1>8$, in gas phase and in the order $3>7>1>8$ in aqueous phase. Moreover, this work opens up new perspectives; in particular, its results could help to identify the mechanisms underlying specific biological properties of 2-thioxanthine.

\section{Acknowledgements}

We would like to thank Professor BAMBA El Hadji Sawaliho for his hepful comments and Professor N'GUESSAN Yao Thomas for his advice.

\section{References}

[1] J. Carbon, H. David, M. H. Studier, Science 1968, 161, 1146.

[2] W. J. Burrows, D. J. Armstrong, F. Skoog, S. M. Hecht, J. T. A. Boyle, N. J. Leonard, J. Occolowitz, Science 1968, 161, 691.

[3] M. Ono, M. Kawakami, J. Biochem. 1977, 81, 1247.

[4] W. Saenge, Soringer, New York, 1984.

[5] S. E. kalyoubi, F. Agili, S. Youssif, Molecules 2015, 20, 19263-19276.

[6] A. Biela1, F. Coste, F. Culard, M. Guerin, S. Goffinont, K. Gasteiger, J. Ciesla, A. Winczura, Z. Kazimierczuk, D. Gasparutto, T. Carell, B. Tudek, B. Castaing, Nucleic Acids Res. 2014, 1-14.
[7] S. L. Maiocchi, J. C. Morris, M. D. Rees, S. R. Thomas, Biochemical Pharmacology 2017, 135, 90-115.

[8] C. J. Weeramange, C. M. Binns, Ch. Chenc, R. J. Rafferty, Journal of Pharmaceutical and Biomedical Analysis 2018, $151,106-115$.

[9] K. Pavelcova, L. Petru, J. Krijt, Toxicology and Applied Pharmacology 2018, 353, 102-108.

[10] S. Deswal, A. Srivastava, Journal of Clinical and Experimental Hepatology 2017, 7(1), 55-62.

[11] Z. Wang, T. M. Rana, Biochemistry 1996, 32, 6491-6499.

[12] D. J. Darensbourg, B. J. Frost, K. A. Derecskei, J. H. Reibenspies, Inorg. Chem. 1999, 38, 4715-4723.

[13] A. Dafali, B. Hammouti, R. Mokhlisse, S. Kertit, Corrosion Sci. 2003, 45, 1619-1630.

[14] O. H. Nielsen, B. Vainer, M. J. Rask, Aliment. Pharmacol. Ther 2001, 15, 1699-1708.

[15] C. E. Neunert, G. R. Buchanan, Pediatr. Blood. Cancer. 2009, $52,5-6$.

[16] M. Raj, R. N. Goyal Sensors and Actuators B 250 2017, 552 562.

[17] E. Kafer Mutation Research. 1975, 31, 347-64.

[18] Scott BR, Kafer E, Dom GL, et al. Mutation Research. 1982; 98: 49-94.

[19] H. G. Mautner, G. Bergson, Acta. Chem. Scand. 1963, 17, 1694.

[20] L. M. Twanmoh Jr., H. B. Wood, J. S. Driscoll, J. Heterocycl. Chem. 1973, 10, 187.

[21] P. U. Civcir. Journal of Molecular Structure (Theochem) 2001; 546, 163-73.

[22] P. U. Civcir. Journal of Molecular Structure (Theochem) 2001; $114,1582-88$

[23] P. U. Civcir. Journal of Molecular Structure (Theochem) 2001; $572,5-13$.

[24] P. U. Civcir, Journal of Molecular Structure-(Theochem) 2001; 545, 7-15.

[25] P. U. Civcir, Journal of Molecular Structure (Theochem) 2001; $536,161-171$.

[26] B. Z. Li, Acta. Phys. Chim. Sin. 2004, 20, 1455-1458.

[27] A. B. Assoma, A. L Bede, M. Kone et al. European Journal of Scientific Research. 2010, 44, 2, 337-354

[28] A. B. Assoma, A. L. Bede, K. D. YAPO et al, European Journal of Scientific Research. 2018; 149, 2, 148-152.

[29] BA Assoma, LA Bede, RB N'Guessan, S Kone, SE Bamba and TY N'Guessan, J Curr Chem Pharm Sc. 2018; 8(2):114.

[30] A. D. Becke The Journal of Chemical Physics. 1997, 107, 8554-60.

[31] M. J. Frisch, G. W. Trucks, H. B. Schlegel, et al. Gaussian Inc. Pittsburgh. 2003.

[32] J. Tomasi, M. Persico Chemical Reviews. 1994, 94, 2027-94. 
[33] E. Canses, B. Mennucci, J. Tomasi, The Journal of Chemical Physics. 1997, 107, 3032-41.

[34] P. G. Mezey, J. J. Ladik, Theor Chim Acta. 1979; 52: 129.

[35] P. G. Mezey, J. J. Ladik,, M. Barry, Theor Chim Acta. 1979; 54: 251 .
[36] M. Remko, J Phys Chem A. 2003, 107, 720-25.

[37] K. N. Rogstad, Y. H. Jang, L. C. Sowers and W. A. Goddard, Chem. Res. Toxicol. 2003, 16, 1455-1462

[38] Y. H. Jang, W. A Goddard, K. T. Noyes, L. C. Sowers, S. Hwang and D. S. Chung, J. Phys. Chem. B 2003, 107, 344357. 